\title{
Research on the Stability Effect of Financial Revenues and Expenditures of Transfer Payments in Minority Regions
}

\author{
HE Chongqi ${ }^{1,2, a}$ \\ ${ }^{1}$ Beijing Normal University , Beijing , 100875 \\ ${ }^{2}$ School of Government , Beijing Normal University ; major : Government Economy Management \\ ahechongqi@126.com
}

Keywords: Minority regions; Transfer payment; Financial revenue; Financial expenditure; Stability effect

\begin{abstract}
As one of the important financial instruments, transfer payments should play the role of stabilizing the economy. Based on the county-level total transfer payment data from 2000 to 2009 in minority regions, this paper empirically studies the impact of fiscal transfer payments, tax returns, the original system subsidies and special transfer payments on the stability of financial revenues and expenditures in minority regions. The results show that fiscal transfer payment has a significant positive effect on the stability of local financial revenues and expenditures at the county level in minority regions; Tax returns and the original system of subsidies have no significant effect on the on the stability of local financial revenues and expenditures at the county level in minority regions; The special transfer payment has a significant effect on the stabilizing county level financial revenues in minority regions, but has no obvious effect on the stabilizing financial expenditures. In order to further enhance the stability effect on the transfer payment, we should improve the transfer payment system that combines the financial transfer payment with the special transfer payment, and appropriately increase the proportion of the two methods.
\end{abstract}

\section{Introduction and Literature Review}

Since the tax sharing reform in 1994, the central government has set up and perfected the inter-government transfer payment system in order to maintain the objectives of equalizing the financial differences among regions and promote the equalization of basic services in various regions while retaining the transfer payments before the reform and settlement of subsidies. With the gradual deepening of the reform of tax-sharing system, the researches on transfer payments in academia have been mainly focused on the equalization effect and the incentive effect of transfer payments on local financial revenue and expenditure but have little attention on the study of the effect of stabilization.

The power hierarchies of our government are five, therefore the corresponding fiscal levels are also five. With the vigorous promotion of "direct provincial supervision of county finance" and "county management of township budget", county governments play increasingly important roles in financial functions. County-level finance is a response to the operating conditions of local finance, which is in the first stage of financial revenue and the final stage of financial expenditure, providing public goods directly to residents in the areas. Therefore, local governments provide local public services more efficiently than the central government. Based on this background, in recent years, academic researches on the transfer payment system has shown concern at the county level.

Musgrave summarized the three functions of modern finance as: resource allocation; redistribution of income and stabilization of the economy. Intergovernmental transfer payment, as an important tool for fiscal policy, has objectives include: providing sufficient flexibility for the central government to stabilize its macroeconomic policies; paying necessary political costs to safeguard national unification and social stability, which should play a role as a stable policy tool. 
Therefore, it is of great significance to study the transfer payment system to stabilize the local financial revenues and expenditures. However, there are few academic researches on related issues.

This paper intends to use the empirical data from the county level in eight minority regions ${ }^{1}$ of China from 2000 to 2009 to study the impact of transfer payments on the stability of local financial revenues and expenditures. Based on the stability index of $\mathrm{Xu}$ Tao and other scholars, this paper takes the county-level overall transfer payments and financial revenues and expenditures as the sources of empirical data and examines the impact of transfer payments on the stability effect of fiscal revenues and expenditures.

B. Models setup and variables descriptions

a.The definition of indicators of stability of financial revenues and expenditures

White proposed using unit standard deviation of tax revenue as an indicator of fiscal stability. Pollock and Suyderhoud used the magnitude of volatility around the trend of fiscal spending as an indicator of stability. Hou further developed test methods of Pollock and Suyderhoud's. And then $\mathrm{Xu}$ Tao further developed Hou's method. This article draws on Xu Tao's approach to measure the stability of financial revenues and expenditures. REVGAP = (logarithm of actual fiscal revenue logarithm of fiscal revenue trend value) / logarithm of fiscal revenue trend value. EXPGAP = (logarithm of actual fiscal expenditure - logarithm of fiscal expenditure trend value) / logarithm of fiscal expenditure trend value. Which is:

$$
\begin{aligned}
& \mathrm{REVGAP}=\left[\ln (\mathrm{REV})-\ln \left(\mathrm{REV}^{*}\right)\right] / \ln \left(\mathrm{REV}^{*}\right) \\
& \mathrm{EXPGAP}=\left[\ln (\mathrm{EXP})-\ln \left(\mathrm{EXP}^{*}\right)\right] / \ln \left(\mathrm{EXP}^{*}\right)
\end{aligned}
$$

(Formula 2.2)

b. Data sources and models setup

Due to the unavailability of data, this paper can only study the empirical situation from 2000 to 2009. The data in this paper are all from the "Fiscal Statistics of Cities and Counties in China" in 2000-2009 compiled by Budget Department and Treasury Department of Ministry of Finance of China.

1. Dependent variable and independent variable

The fixed effect model is used to calculate the fitted value of actual fiscal revenues and expenditures across the country. In order to eliminate the attributes of time series, the natural logarithm is used as the dependent variable of regression, the regression equations are as followed:

$$
\begin{aligned}
& \operatorname{Ln}\left(\operatorname{REV}_{\mathrm{it}}{ }^{*}\right)=\alpha_{\mathrm{i}}+\beta_{\mathrm{i}} \mathrm{T}_{\mathrm{t}} \\
& \operatorname{Ln}\left(\mathrm{EXP}_{\mathrm{it}}{ }^{*}\right)=\alpha_{\mathrm{i}}+\beta_{\mathrm{i}} \mathrm{T}_{\mathrm{t}}
\end{aligned}
$$

Where: $\mathrm{REV}_{\text {it }}$ represents the actual value of i's fiscal revenue at year $\mathrm{t} ; \mathrm{REV}_{\mathrm{it}}$ * represents the trend of i's fiscal revenue at year t; EXP it represents the actual value of i's fiscal expenditure at year $t$; $\mathrm{EXP}_{\mathrm{it}}$ * represents $\mathrm{i}$ the trend of i's fiscal expenditure at year $\mathrm{t}$; $\mathrm{T}_{\mathrm{t}}$ represents the annual value at year $t$.

The main variables of this paper are four categories of fiscal transfer payments, tax return, the original system of subsidies and special transfer payments.

\section{Empirical settings}

Fixed effect was used for empirical test to eliminate the time-series attributes of the independent variables, all the independent variables adopted their natural logarithm as regression independent variables. The regression equations are as followed:

$$
\begin{aligned}
& \text { RREVGAP }_{\mathrm{i}, \mathrm{t}}=\alpha^{\mathrm{i}}+\beta_{\mathrm{t}}+\gamma_{1} \ln (\mathrm{FTP})+\gamma_{2} \ln (\mathrm{TRR})+\gamma_{3} \ln (\mathrm{OSS})+\gamma_{4} \ln (\mathrm{STP})+\varepsilon_{\mathrm{i}, \mathrm{t}} \\
& \text { EXPGAP }_{\mathrm{i}, \mathrm{t}}=\alpha_{\mathrm{i}}+\beta_{\mathrm{t}}+\gamma_{1} \ln (\mathrm{FTP})+\gamma_{2} \ln (\mathrm{TRR})+\gamma_{3} \ln (\mathrm{OSS})+\gamma_{4} \ln (\mathrm{STP})+\varepsilon_{\mathrm{i}, \mathrm{t}}
\end{aligned}
$$

1 Minority regions include: Inner Mongolia Autonomous Region, Guangxi Zhuang Autonomous Region, Tibet

Autonomous Region, Ningxia Hui Autonomous Region, Xinjiang Uygur Autonomous Region; and Guizhou Province, Qinghai Province and Yunnan Province. 
Where $\alpha_{i}$ represents the effect of a fixed province; $\beta_{t}$ represents the effect of a fixed year; FTP represents fiscal transfer payments; TRR represents tax return; OSS represents the original system of subsidies; STP represents special transfer payments.

C. Empirical tests and results interpretation

a. Panel data regressions results

This paper uses the panel data of the county level in eight minority regions from 2000 to 2009 to make regression. The regression model is shown in Table 1 using the fixed effect model.

Table 1 The regression results on stability effect of stability effect of financial revenues and expenditures of transfer payment in minority regions

\begin{tabular}{ccc}
\hline Dependent variable & $\begin{array}{c}\text { Financial income stability } \\
\text { index(RevGap) }\end{array}$ & $\begin{array}{c}\text { Financial expenditure stability } \\
\text { index(ExpGap) }\end{array}$ \\
\hline Fiscal transfer payment & $\begin{array}{c}0.014350^{* * *} \\
(3.638865)\end{array}$ & $\begin{array}{c}0.015289 * * * \\
(3.720108)\end{array}$ \\
tax return & 0.000791 & $0.0038-2$ \\
the original system of & $(0.266452)$ & $(1.229413)$ \\
subsidies & 0.003965 & 0.003449 \\
special transfer payment & $(0.979293)$ & $(0.817552)$ \\
& $0.006707^{* * *}$ & 0.003624 \\
constant & $(2.918781)$ & $(1.513182)$ \\
$\mathrm{R}^{2}$ & $-0.326504 * * *$ & $-0.327624 * * *$ \\
Adjusted $\mathrm{R}^{2}$ & $(-3.767890)$ & $(-3.627833)$ \\
\hline
\end{tabular}

Note: $1 . * * *, * *, *$ indicate that the estimated coefficients are significant at the levels of $1 \%, 5 \%$ and $10 \%$, respectively;

2. Numbers in brackets are t values.

b. Empirical results analysis

1.Effect of fiscal transfer payment. The stability of fiscal transfer payment on the local revenues and expenditures in minority regions is significant at $1 \%$ level and the coefficient is positive, indicating that the fiscal transfer payment has a significant positive effect on stability effect of local fiscal revenues. From the data, the proportion of the central government's transfer of financial resources to minority regions is growing in transfer payments. As one of the important sources of county level financial revenues, the increase of fiscal transfer payment is conducive to enhancing the predictability of obtaining local fiscal transfer payments from local governments in minority regions, which helps to maintain the stability of local financial revenues.

2. Effect of tax return. The empirical results show that tax returns have no significant effect on the stability of local financial revenues and expenditures in minority regions. From 2000 to 2009, the proportion of tax returns in minority regions as a percentage of total transfer payments decreased year by year, from $19.42 \%$ to $4.23 \%$. Even though the total amount of tax return at the county level in minority regions increased year by year, its effect on increasing the predictability of local financial revenues can not be realized because of its low share of total transfer payments. In addition, tax returns are closely linked with the growth rates of the national VAT and GSTs as well as the regional economic conditions, resulting in equally unpredictable tax returns in the regions.

3. Effect of the original system of subsidies. The impact of the original system of subsidies on the stability of local financial revenues and expenditures is not significant in minority regions. In 
general, the original system of subsidies is a form of subsidies temporarily reserved for ensuring the continuity of the fiscal system. From the perspective of county level in minority regions, the share of the original system of subsidies in total transfer payments has been decreasing year by year. In 2000 , the original system of subsidies accounted for nearly $20 \%$ of local transfer payments, but by 2009 it was reduced to less than $2 \%$. Its smaller proportion can not give a clear effect on the stability of financial revenues and expenditures in minority regions.

4. Effect of special transfer payment. The stability of special transfer payment on the local revenues and expenditures in minority regions is significant at $1 \%$ level and the coefficient is positive, indicating that the special transfer payment has a significant positive effect on stability effect of local fiscal revenues. During the period from 2000 to 2009, the proportion of special transfer payments at the county level in minority regions generally showed a U-shaped trend as a whole in transfer payments. In general, the central government's special transfer payment to local cities has a certain degree of stability, and to a certain extent, it has also played a positive role in stimulating the stability of financial revenue in minority regions. However, since the special transfer payments in many minority regions present project characteristics, after the end of project, the central government will stop such special transfer payment.Therefore, the central government's special transfer payments to minority regions are also somewhat unstable.

In fact, in addition to the four types of transfer payments discussed in this paper, there are still many factors that have impacts on the stability of local financial revenues and expenditures. Although this paper examines the impacts of four types of transfer payments on the stability of local financial revenues and expenditures in minority regions through empirical models, it can not be concluded that county level financial revenues and expenditures in minority regions are stable, and other empirical models are still needed for testing.

D. Conclusion and policies suggestions

This paper mainly examines the stability of financial revenues and expenditures in eight minority regions during the period from 2000 to 2009 on the overall county level, and the influences of four types of transfer payments: fiscal transfer payment, tax return, the original system of subsidies and special transfer payment. The intergovernmental transfer payment system should play its stabilizing role as a financial tool. As an important participant in macroeconomic stability, the central government plays an indispensable role in realizing the country's economic stability. Based on the fact that there is a large gap between urban and rural areas in China, the central government should establish a reasonable transfer payment system to balance the vertical and horizontal financial gaps between regions. From the perspective of the forms of transfer payment, the model of transfer payment mainly based on fiscal transfer payment and special transfer payment should be perfected, and the transfer payment structure should be adjusted so that it can play an appropriate role in stabilizing the economy.

\section{References}

[1] Xu Tao. An Empirical Analysis of Transfer Payments on the Stability Effect of Local Financial Revenues and Expenditures[M]. Beijing: China Taxation Publishing House, 2013.3.

[2] Sun Kai. Research on the Optimization of the Methods of Financial Transfer Payments Integration and Distribution[J]. Finance\$Trade Economics, 2009(7): 45-49.

[3]White, Fred C., Trade-off in Growth and Stability in State Taxes[J], National Tax Journal, Mar 1983, Vol.36 Issue 1, 103-114.

[4]Hou Yilin. Fiscal Reserves and State Own-Source Expenditure in Downturn Years [J], Public Finance Review, January 2005, Vol.33 No.1,117-144.

[5]Pollock, Richard and Suyderhoud, Jack P., The Role of Rainy Day Funds in Achieving Fiscal Stability [J], National Tax Journal, 1986, Vol.39(4), 485-497. 